rerence

Art, Illustration and Visual Culture

in Infant and Primary Education

\title{
Transdisciplinariedad en arte en primaria: el repensar de una propuesta curricular
}

\author{
Sheila Maddalozzo sheilamaddalozzo@gmail.com \\ Maria Cristiane Deltregia Reys cris_reys@hotmail.com \\ Débora Rocha Gaspar debygaspar@gmail.com \\ Colégio de Aplicação UFSC, Brasil
}

Reference

Maddalozzo, Sheila; Reys, Maria Cristina Deltregia; Gaspar, Débora Rocha; (2012) "Transdisciplinariedad en arte en primaria: el repensar de uma propuesta curricular", p. 158-162 . In: Barbosa, Helena; Quental, Joana [Eds]. Proceedings of the 2nd International Conference of Art, Illustration and Visual Culture in Infant and Primary Education. São Paulo: Blucher, 2015. ISSN 2318-695X, ISBN: 978-989-98185-0-7

DOI 10.5151/edupro-aivcipe-31

Resumen

El Grupo de Investigación EBA - Educación Básica y Arte congrega profesores de Música, Teatro y Artes Visuales del Colégio de Aplicacão de la Universidade Federal de Santa Catarina y pretende desarrollar acciones pedagógicas y prácticas expresivas que vengan contribuir con la enseñanza de Arte en la Educación Básica. La primera estrategia en 2012 del Grupo EBA es una investigación con las tres clases del primer año de Primaria del CA-UFSC en los lenguajes de Teatro, Música y Artes Visuales, de forma interdisciplinaria y por Proyectos de Trabajo. Partiendo de una perspectiva cualitativa, el estudio propone un abordaje de investigaciónacción. Barbier (1985), Duncum (2011), Hernández (2007) y Tomaz Tadeu da Silva (2002) son algunas referencias en la búsqueda de un estudio curricular innovador del tipo Integrado, en que las distinciones entre las aéreas de conocimiento son poco marcadas.

Arte, Educación Básica, Transdiciplinariedad, Proyectos de Trabajo.

Abstract

The Research Group EBA - Basic Education and Arts gathers teachers of Music, Theatre and Visual Arts Colégio de Aplicação of the Universidade Federal Santa Catarina and aims to develop educational actions and expressive practices that contribute to the teaching come from Art in the Basic Education. The first strategy in 2012 EBA is a research group with the three classes the first year of Primary CA-UFSC in the languages of Theatre, Music and Visual Arts, an interdisciplinary and Work Projects. From a qualitative perspective, the study proposes an action research approach. Barbier (1985), Duncum (2011), Hernandez (2000, 2007) and Tomaz Tadeu da Silva (2002) are some references in the search for innovative curricular study, Integrated type, in which the distinctions between the areas of knowledge are little marked.

Keywords

\section{Introducción}

El Grupo de Investigación EBA - Educación Básica y Arte, creado en 2011, es formado por los docentes de Arte del Colégio de Aplicação de la Universidade Federal de Santa Catarina (CA-UFSC) ubicada en Florianópolis, Brasil. Este grupo de investigación tiene como objetivo desarrollar acciones pedagógicas y prácticas expresivas que vengan contribuir con la enseñanza de Arte en la Educación Básica. El EBA pretende repensar la estructura curricular vigente en el CA-UFSC, para ajustar las recientes orientaciones nacionales del Ministerio de Educación (BRASIL: Ministério da Educação, 2010) que plantea un mínimo de 20\% (veinte por ciento) del total de la carga de trabajo anual al conjunto de programas y proyectos interdisciplinares electivos creados por la escuela en Secundaria. 
2nd International Conference Art, Illustration and Visual Culture in Infant and Primary Education $2^{\circ}$ Congreso Internaciona

Arte, Ilustración y Cultura Visual en Educación Infantil y Primaria
${ }^{\circ}$ Congresso Internacional

de Arte, Ilustração e Cultura Visual

na Educação Infantil e Primária

\section{Relato en múltiples voces: experiencia transdisciplinaria}

Figuras 1,2 y 3 . Estudiantes en el auditorio del CA/UFSC (Florianópolis, Brasil), donde formaran grupos por personajes del circo e hicieran el dibujo diagnóstico. Fuente: propia
Tal perspectiva interdisciplinar ha sido analizada por autores como Zabala (2000) y Domingues (2005), y entendida como instigadora de prácticas pedagógicas significativas, que congregan saberes de distintos dominios del conocimiento. Zabala (2002) comprende la interdisciplinariedad como una cooperación entre diversas asignaturas que se traduce en un mismo conjunto de conceptos y métodos de investigación, sobresaliendo que la interrelación de las asignaturas con sus especificidades puede proporcionar una mayor comprensión de la realidad, la cual es siempre de "naturaleza compleja", conforme plantea Morin (2000).

Como estrategia inicial, en 2012, el Grupo EBA propuso actuar en tres clases del primer año de Primaria en el CA/UFSC en los lenguajes de Teatro, Música y Artes Visuales, de forma interdisciplinar y por Proyectos de Trabajo (HERNÁNDEZ, 2007). La propuesta es integrar las clases $A, B$ y $C$ en un proyecto que proporcione vivencias en diferentes lenguajes artísticas en clases guiadas por el devenir del proyecto.

Presentamos nuestras primeras observaciones de esta propuesta interdisciplinar en las clases del primer año, donde construimos narrativas que reflejan sobre la experiencia vivida en una escritura en "múltiples voces", por consistir en una elaboración textal compartida entre las profesoras-investigadoras.

Los estudiantes de los primeros años tienen tres clases de Arte semanales, que hasta entonces eran separadas por lenguajes artísticas. Para mejor ajustar la propuesta interdisciplinar, en este año, las clases ocurren todas en el mismo día y en secuencia.

Después del primer contacto con los niños y niñas, se ha delineado el tema a ser trabajado - el "Circo" - por mostrarse de gran interés de todos. En el auditorio de la escuela, a partir de la apreciación de la canción "O Palhaço e a Bailarina" de Cecília França, los estudiantes realizaran un dibujo diagnóstico, que nos iba permitir conocer sus referencias culturales sobre el tema. A continuación, fueran formados tres grupos: payasos, bailarines y músicos, según los intereses de cada uno. En este momento, hubo una primera y grande mescla de las clases originarias, resultante de las elecciones personales. La junción de los sesenta alumnos fue bastante caótica, pero se ha revelado muy significativa a todos.

No final da tarde, os rastros de papel crepon sobre o palco vazio traziam a vivacidade daquela experiência e a sensação de que realmente uma dinâmica interdisciplinar e multilinguística entre as artes era possível de ser construída e que talvez para isso, assim como nas pós-vanguardas artísticas, tais práticas deveriam ser constituídas pelo acaso, performances, assemblages e rizomas, rompendo com as pedagogias tradicionais que povoam o espaço escolar. As crianças traziam seus pais pelas mãos para mostrar o local onde haviam tido aula de Arte naquela tarde, ávidos por narrar a experiência que haviam vivenciado. Será que os momentos caóticos de trocas entre os pares também não gerou uma forma de conhecimento para aquelas crianças? Um conhecimento empírico e interpessoal, subjetivo do ser criança em um espaço que lhes permitiu rir e brincar, imaginar e conhecer o outro? (Diário de Campo).

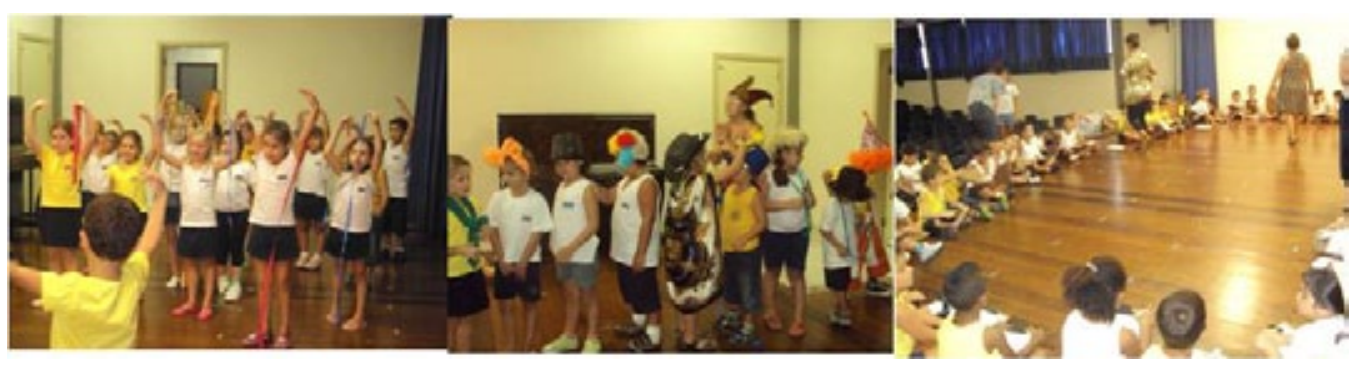

En las semanas siguientes observamos imágenes producidas por artistas como Seurat, que abordan la temática circense, escenas del Cirque du Soleil y de la película The Circus de Chaplin. Las estrategias educativas realizadas con esos materiales apuntaban a las relaciones entre el arte y el imaginario de la cultura popular propuestas por los Estudios de la Cultura Visual. Segundo Hernández (2007): 
$2^{\text {nd }}$ International Conference Art, Illustration and Visual Culture in Infant and Primary Education $2^{\circ}$ Congreso Internacional

Arte, llustración y Cultura Visual en Educación Infantil y Primaria
Congresso Internacional

de Arte, llustração e Cultura Visual

na Educação Infantil e Primária

Figuras 4 y 5 A la izquierda: estudiantes produciendo la ropa del mágico. CA-UFSC, Florianópolis, Brasil. A la derecha: en el aula de música creando las sonorizaciones para las escenas de los personajes del circo. CA-UFSC Florianópolis, Brasil. Fuente: propia.

\begin{abstract}
Esta vinculación puede ser interesante para los educadores del campo de las artes visuales porque les permite transitar de lo conocido hasta el desconocido. Pero también porque permiten establecer puentes, en forma de apropiaciones (procedimiento que está en el fundamento de las prácticas artísticas) entre la cultura visual popular y las artes visuales que podrían considerarse como tradicionales y que al relacionarse en situaciones de intertextualidad produce nuevas representaciones y significados. (HERNÁNDEZ, 2007:50)
\end{abstract}

Los estudiantes también han elaborado marionetas de sus personajes preferidos, los presentaran escénicamente y crearan la sonorización de las escenas: el sonido de la caída del payaso, el baile de las bailarinas, la tensión del equilibrista en la cuerda floja y el suspense en el momento de la mágica.
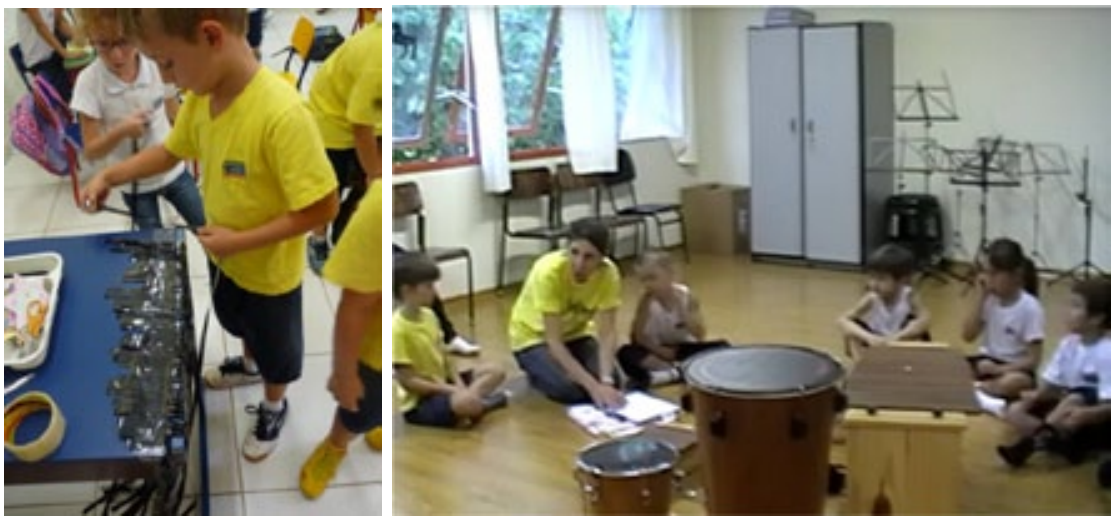

En la contemporaneidad, la Educación Musical comprende la sonorización de las escenas como una actividad de composición, prioritaria para desarrollar el conocimiento en Música y el hacer musical en la clase. En esta fase inicial de musicalización, las actividades de composición lúdicas permiten explorar y experimentar "possibilidades expressivas dos sons e sua organização" (FRANCA e SWANWICK, 2002:10). Esta experimentación que "demanda ouvir, selecionar, rejeitar e controlar o material sonoro" (ibid.) ha permitido que la sonorización de las escenas pudiesen transferir las experiencias vividas en los lenguajes de Teatro y Artes Visuales para el sonido.

El uso de los animales en el circo ha surgido como un tema transversal. Así, la controvertida figura del domador de animales fue interpretada por la profesora de Teatro, en una vivencia por el drama (CABRAL, 2006), "um processo coletivo de construção de uma narrativa dramática, estimulando os participantes a conceberem teatralmente uma história" (DESGRANGES, 2010: 125). En esta narrativa por el drama, el domador, acusado de dañar los animales, se ve desempleado y los alumnos divididos en grupos de personajes circenses (payaso, equilibrista, músico, mágico y bailarina) deberían enseñarle otro oficio, utilizando los materiales construidos con antelación en las clases.

\begin{abstract}
O Drama constitui-se, assim, em uma experiência que solicita a adesão e a cooperação dos diversos integrantes do grupo. Podemos compreendê-lo como uma forma de arte coletiva, em que os participantes (coordenador e grupo) assumem as funções de dramaturgos, diretores, atores, espectadores, etc. (...) Esses episódios que estruturam as sessões de Drama podem ser compostos por atividades diversas: a narração ou leitura de partes de história; a proposição de jogos de improvisação teatral ou de jogos lúdicos; a concepção e a construção de objetos cênicos; a exploração e criação de músicas e sonoridades. (DESGRANGES, 2010: 125, 127)
\end{abstract}

La temática se ha concluido con la exposición de los estudiantes/personajes en el auditorio: payasos, mágicos, equilibristas y bailarinas se presentaran al sonido de las sonorización creadas por ellos. La problemática del domador, por su vez, ha introducido la temática siguiente - los animales - tema que está siendo desarrollado en el según trimestre, teniendo como referencia el musical, "Os Saltimbancos", de Chico Buarque de Holanda. 
$2^{\text {nd }}$ International Conference Art, Illustration and Visual Culture in Infant and Primary Education
Figuras 5 y 6. Profesoras de Teatro en el momento de la vivencia por el drama. Fuente: propia
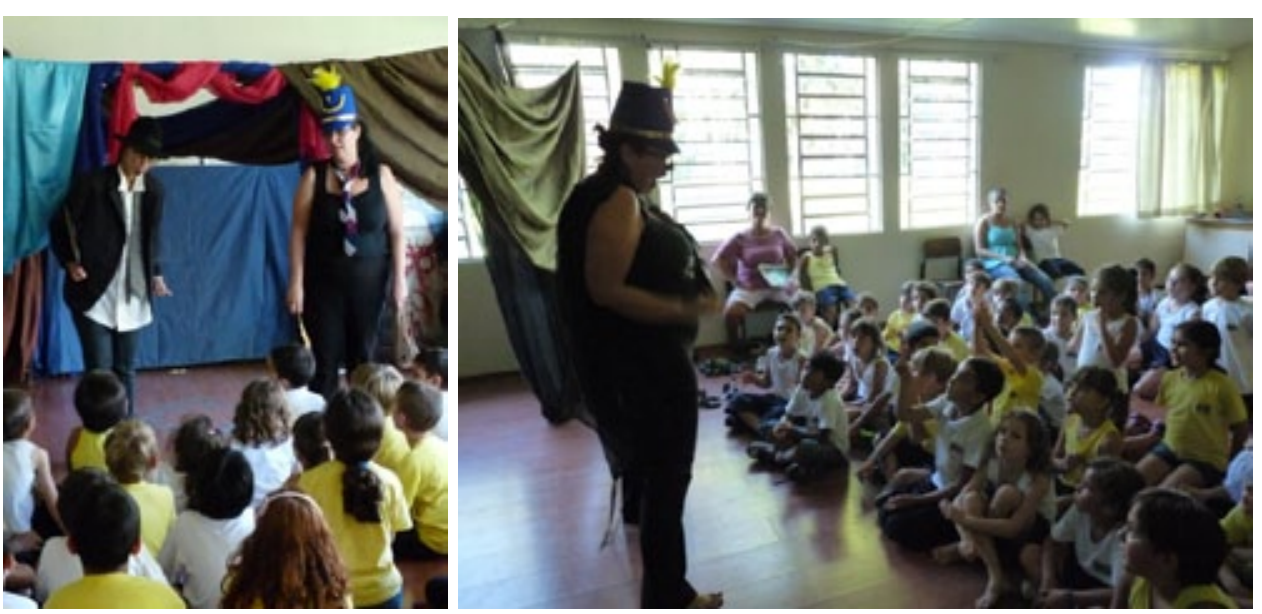

En el transcurrir de este primer proyecto interdisciplinar de investigación percibimos varios aspectos relevantes, tanto de orden organizacional como ideológico/conceptual.

La ruptura de la estructura formal preestablecida de clases A, B y C parece bien sucedida, aunque solamente hemos realizado algunas veces. Considerando que los niños y niñas llegan a la escuela en este año y que aún están construyendo sus referenciales, optamos por mesclar, efectivamente, las clases solamente en el según trimestre. Así, en los próximos encuentros las clases serán reorganizadas en cinco nuevos grupos de trabajo, mesclando alumnos de las tres clases.

El hecho de tener las tres clases de Arte en secuencia en los tres grupos de estudiantes del primer año de Primaria nos ha permitido romper el paradigma del horario y de los tiempos predefinidos, extendiendo acciones que requerían mayor tiempo, lo que es una gran ventaja delante del sistema rígido de la escuela convencional. En este sentido, fue imprescindible la cooperación de los dirigentes del Colegio, sensibles a nuestra propuesta, comprobando que su complicidad es indispensable al desarrollo de proyectos interdisciplinarios.

Conceptualmente, la distinción entre los lenguajes artísticos se ha revelado más aparente entre las profesoras que entre los estudiantes, que percibieran las clases de Arte como un todo, no categorizando los lenguajes aisladamente. El planeamiento y la evaluación de las propuestas, la sintonía entre las profesoras actuantes y las demás acciones conjuntas han ultrapasado la interdisciplinariedad, llegando a la transdiciplinariedad (Zabala, 2000). La transdiciplinariedad consiste en el grado máximo de relaciones entre las asignaturas, supone una integración más global y favorece una unidad interpretativa con el objetivo de construir una ciencia que explique la realidad sin comparticiones, como es la arte en la contemporaneidad. Además determina ciertas relaciones de contenidos con pretensiones integradoras.

La relación de cooperación en la práctica pedagógica transciende las afinidades personales, abarca concepciones de enseñanza y aprendizaje, además requiere un compromiso constante y autocrítico. La evaluación continua del proceso es indispensable y a la vez expone las fragilidades del recorrido y además revelan los aspectos positivos que direccionan el caminar. 
2nd International Conference Art, Illustration and Visual Culture in Infant and Primary Education $2^{\circ}$ Congreso Internacional Arte, llustración y Cultura Visual en Educación Infantil y Primaria
Congresso Internacional de Arte, llustração e Cultura Visual na Educação Infantil e Primária

\section{Referencias bibliográficas}

BRASIL. Resolução n 4 de 13 de julho de 2010, Câmara de Educação Básica. Brasil: Ministério da Educação, 2010.

CABRAL, Beatriz Angela Vieira. O Drama como método de ensino. São Paulo: Hucitec, 2006.

DESGRANGES, Flávio. A pedagogia do teatro: provocação e dialogismo. $2^{a}$ Ed. São Paulo: editora Hucitec: edições Mandacaru, 2010

DOMINGUES, Ivan. Org. Conhecimento e transdisciplinaridade II: Aspectos Metodológicos. Belo Horizonte: Editora UFMG, 2005

FRANÇA, Cecília C.; SWANWICK, Keith. Composição, apreciação e performance na educação musical: teoria, pesquisa e prática. Revista Em Pauta, v. 13, n. 21, p. 5-41. Porto Alegre: UFRGS, 2002.

HERNÁNDEZ, F. Espigadores de La cultura Visual: otra narrativa para la educación de las artes visuales. Barcelona: Octaedro, 2007.

MORIN, Edgar. Os Sete Saberes necessários à Educação do Futuro. São Paulo/Brasília, Cortez/UNESCO, 2000.

UFSC - CED - CA, Regimento Escolar do Colégio de Aplicação. Florianópolis: UFSC, 2007.

ZABALA, Antoni. Enfoque globalizador e pensamento complexo: uma proposta para o currículo escolar. Trad. Ernani Rosa. Porto Alegre: ARTMED, 2002. 